\title{
AS CONTRIBUIÇÕES HISTÓRICAS DE PAULO FREIRE NO QUE SE REFERE AO DIREITO DO ADULTO À EDUCAÇÃO E O SEU MÉTODO DE ALFABETIZAÇÃO
}

\author{
Carla Luz SalaibB DotTa \\ Universidade Estadual do Rio Grande do Sul (UERGS), Osório, Rio Grande do Sul, Brasil \\ ELISETE ENIR BERNARDI GARCIA \\ Universidade Federal do Rio Grande do Sul (UFRGS), Rio Grande do Sul, Brasil
}

\begin{abstract}
Resumo: O presente texto trata da trajetória de vida do educador Paulo Freire, apresentando sua história não somente como homem social, como é conhecido, mas como ser humano e educador, baseado em uma revisão bibliográfica feita em torno da história de sua vida, fundamentada nos estudos de Sergio Haddad (2019), Moacir Gadotti (2004) e nas obras do próprio Freire. Este estudo integra uma pesquisa de Mestrado Profissional em Educação, que investiga acerca dos estudantes de um curso superior que passaram em suas trajetórias escolares pela Educação de Jovens e Adultos - EJA. Para que esse estudo fosse realizado, foi fundamental o embasamento teórico dos conceitos de Paulo Freire, o que nos despertou interesse não somente em compreendermos os conceitos em si, mas também conhecermos sua história, chegar mais perto da vida desse educador popular que se dedicou aos excluídos, oprimidos e analfabetos.
\end{abstract}

PalavaAs-chave: Paulo Freire. História. Alfabetização. Educação de Jovens e Adultos.

\section{INTRODUÇÃO}

Todo contexto histórico do Brasil que envolve sujeitos da Educação de Jovens e Adultos está inegavelmente relacionado à vida e aos conceitos de Paulo Freire. Paulo Freire está entre os educadores que mais contribuíram para o avanço do direito à educação de adultos, não somente no Brasil, mas em muitos outros países nos quais trabalhou durante o período de seu exílio por conta da Ditadura Militar do Brasil.

Por isso, o presente texto trata da trajetória de vida do educador Paulo Freire, apresentando sua história não somente como homem social, como é conhecido, mas como ser humano e educador, baseado em uma revisão bibliográfica feita em torno da história de sua vida, fundamentada nos estudos de Sergio Haddad (2019), Moacir Gadotti (2004) e nas obras de Paulo Freire.

Esse recorte busca contribuir para as reflexões que estão sendo realizadas em torno das comemorações do centenário de Paulo Freire e integra uma pesquisa maior que está vinculada ao Mestrado Profissional em Educação, que investiga acerca dos estudantes de um curso superior que passaram em suas trajetórias escolares pela Educação de Jovens e Adultos - EJA e tem como interlocutores, estudantes do curso superior de Licenciatura em Educação do Campo - Ciências da Natureza da Universidade 
Federal do Rio Grande do Sul (UFRGS), que passaram em suas trajetórias escolares pela modalidade EJA.

Com o objetivo de compreender as diversas formas de ingresso ao Ensino Superior no Brasil, no desenvolvimento da pesquisa mencionada acima, foi necessário um estudo de como as políticas de acesso a esse nível de educação se projetam no cenário brasileiro e, principalmente, o quanto essas políticas podem contribuir para a manutenção da desigualdade social e educacional, ainda que se afirmem como políticas de acesso. Pois, a pesquisa trata não somente do direito a uma educação de qualidade que subsidie a continuidade dos estudos, mas do alcance de um sonho que permeia a vida de sujeitos que retomam seus estudos na modalidade EJA, independente da condição que os tenha levado a frequentá-la, sendo essencial para esse estudo um embasamento teórico-metodológico dos conceitos freireanos no que se refere ao direito dos sujeitos de se perceberem como participantes sociais e políticos do processo de emancipação e libertação.

Nesse sentido, para que fosse possível estabelecer a relação entre os estudos, conceitos e contribuições de Paulo Freire como principal referencial teórico da pesquisa, tornou-se necessário conhecer sua trajetória; não somente suas ideias, mas também sua história de vida e os caminhos que o levaram ao desejo de lutar para dar voz aos adultos analfabetos no sentido de se compreenderem como sujeitos de direito e participantes da sociedade e, dessa forma, chegar mais perto da vida desse educador popular que por dedicar-se aos excluídos, oprimidos, analfabetos foi exilado. Mas que, paradoxalmente, "Ihe deu acesso ao mundo e acesso do mundo a ele" (CASALI, 2006, p. 19).

Ao buscarmos pesquisas anteriores para a construção do estado da arte, percebemos que muitos trabalhos estão ancorados em pressupostos freireanos, mas poucos contextualizam a história de vida de Freire. Assim, buscamos compreender como aconteceu a inserção de Paulo Freire no contexto educacional do direito à educação, principalmente de adultos, no Brasil, buscando conhecê-lo não apenas como referencial teórico de nosso trabalho, mas apresentá-lo a partir da beleza de sua história fragmentos da trajetória de vida do educador, não somente como homem social, como é conhecido, mas como ser humano - e do quanto isso enriquece a trajetória históricosocial da educação de nosso país.

Nesse sentido, um dos aspectos que nos pareceu importante destacar no texto aqui apresentado foi o Método Paulo Freire de alfabetização. Da mesma forma que seus conceitos são utilizados como referencial, seu método de alfabetização é conhecido mundialmente, mas como toda pesquisa se constitui pelo desejo de conhecer mais, buscamos entender como se deu o desenvolvimento dos pensamentos relacionados a metodologias de alfabetização, que o levaram a criar então o que conhecemos hoje como "Método" Paulo Freire.

\section{PAULO FREIRE - TRAJETÓRIA, VIDA E EDUCAÇÃO}

A década de 1950 foi marcada não somente pelo surgimento dos movimentos populares e das campanhas de alfabetização de adultos, mas principalmente pelo início da presença marcante de Paulo Freire e de suas experiências com a educação de 
DOTTA, C. S. S.; GARCIA, E. E. B.

adultos. Paulo Reglus Neves Freire ganhou os olhares, não só do Brasil, mas do mundo, com o seu conhecido Método Paulo Freire de Alfabetização de Adultos, que defendia o direito do povo à educação e afirmava que muito mais importante que a leitura da palavra era a leitura crítica do mundo (FREIRE, 2020).

Para Gadotti (2011), até o final dos anos de 1940, a educação de adultos vinha sendo concebida como extensão da escola formal e entendida como democratização da escola, principalmente para as zonas rurais. Já no final dos anos de 1950, o autor afirma que duas eram as tendências mais significativas de educação de adultos: a educação funcional (profissional), projeto que visava ao desenvolvimento e treinamento da mão de obra, e a educação libertadora - a educação pela conscientização defendida por Paulo Freire.

Formado em Direito pela Faculdade de Direito de Recife em 1947, Freire até se arriscou no serviço de advocacia por um curto período, porém, "a expectativa de trabalhar como advogado era sempre confrontada com a atividade de professor, que já exercia e que tanto o atraia" (HADDAD, 2019, p. 38). Deixou a profissão de advogado pouco tempo depois, ao aceitar o convite para trabalhar na Divisão de Educação e Cultura do Serviço Social da Industria (SESI), onde permaneceu por 10 anos.

No decorrer do período que trabalhou no SESI, Freire se manteve envolvido com inúmeros programas que o aproximavam cada vez mais da educação dos trabalhadores. Publicou vários artigos e participou de muitos congressos e seminários. Haddad (2019) relata que em 1948, Freire, sua esposa Elza e outros voluntários elaboraram um relatório para o II Congresso Nacional, com o título: a Educação de Adultos e as populações marginais: O problema dos mocambos. O relatório sugeria uma crítica ao assistencialismo que ele percebia através do seu trabalho e que a ação alfabetizadora deveria proporcionar à população excluída uma maneira de sair dessa condição de marginalizados e participar ativamente da vida política do país. Tal relatório tornou-se referência para a educação de jovens e adultos após ser publicado nos anais do evento.

Em paralelo com seu trabalho no SESI, foi nomeado professor catedrático interino de História e Filosofia da Educação na Faculdade de Belas Artes de Recife. Em 1959 defendeu sua tese de doutorado com o tema: Educação e Atualidade Brasileira. Segundo Haddad (2019), a partir desse trabalho suas pesquisas ganharam imensa repercussão e dimensão nacional, garantindo o prestígio para dar continuidade às suas pesquisas, porém as ideias apresentadas por Freire em sua tese também despertaram desconfiança e perseguição, que acabaram levando-o ao exílio após o golpe militar de 1964.

No ano de 1961, foi nomeado como professor na Faculdade de Filosofia, Ciências e Letras da Universidade de Recife, onde inaugurou e coordenou o Serviço de Extensão Cultural (SEC), no ano seguinte foi convidado pelo prefeito de Recife para integrar o Movimento de Cultura Popular (MCP). Esse movimento buscava atender à elevada demanda por escolarização; ainda que inicialmente priorizasse a educação de crianças, acabou por se estender também aos adultos nos Centros de Cultura Popular, tendo Paulo Freire tomado a frente do setor de educação destinado aos adultos. O que, segundo Paiva (2015, p. 368), "representou uma etapa importante no desenvolvimento das ideias que estarão presentes na teorização e na metodologia elaborada por Paulo 
Freire". Entre setembro de 1961 e fevereiro de 1963, o MCP realizou uma experiência de educação pelo rádio, com recepção organizada em escolas experimentais.

Com a grande quantidade de adultos fazendo parte do movimento e com programas de alfabetização e pós-alfabetização, Paulo Freire percebe a necessidade de construção de um material didático específico de apoio aos monitores que trabalhavam com a alfabetização desses adultos. Foi elaborado, então, um livro de leitura para adultos, como um instrumento de cultura na busca da emancipação de adultos. Porém, Freire nunca fora favorável ao uso de cartilhas, pois as considerava externas ao processo educativo e acreditava que esse material não estimulava o aluno a pensar a partir de seu cotidiano, porém, caso não apresentasse uma metodologia adequada, não poderia evitar sua utilização (HADDAD, 2019). A partir de então, passou a estudar formas de desenvolver um material alternativo. Freire entendia que a alfabetização era um processo que deveria considerar a construção da autonomia do sujeito e não sua redução a objeto aprendente:

\begin{abstract}
a alfabetização não se pode fazer de cima para baixo, nem de fora para dentro, como uma doação ou uma exposição, mas de dentro para fora, pelo próprio analfabeto, somente ajustado pelo educador. Esta é a razão pela qual procuramos um método que fosse capaz de se fazer instrumento também do educando e não só do educador e que identificasse o conteúdo da aprendizagem com o processo de aprendizagem. Por essa mesma razão, não acreditamos nas cartilhas, que pretendem fazer uma montagem de sinalização gráfica como uma doação e que reduzem o analfabeto mais à condição de objeto de alfabetização do que de sujeito da mesma (FREIRE, 2013, p. 86).
\end{abstract}

\title{
O “MÉTODO” PAULO FREIRE E AS CAMPANHAS DE ALFABETIZAÇÃO DE ADULTOS
}

Freire, como educador-pesquisador, estava sempre atento, se questionando sobre os processos de ensinar e aprender, o que o levou a perceber que recursos como materiais visuais em formato de cartazes, desenhos ou slides fluíam melhor nas reuniões que participava, e o que lhe fez pensar em desenvolver algo semelhante também para a alfabetização. Em uma determinada ocasião, Freire passou por uma experiência com seu filho de três anos de idade, que ao ver a imagem de uma lata de achocolatado no ponto de ônibus, o menino que costumava assistir a propaganda na televisão, apontou para a lata, falou a palavra "Nescau" e cantou a música que escutava na propaganda. Freire se surpreendeu ao perceber que de certa forma seu filho leu a palavra Nescau. A partir desse episódio, passou a elaborar um método que conectasse as palavras às imagens incorporando-as às experiências dos educandos, conforme relata Haddad (2019).

Com parte do material preparado, convidou Maria - uma senhora que os auxiliava nos cuidados com a casa e com seus filhos, e que não sabia ler e escrever - a participar de uma experiência de alfabetização. Com a imagem de um menino e da palavra escrita, percebeu que Maria conseguia, mesmo sem saber ler, fazer associações entre a imagem e a palavra escrita e que ao retirar a primeira sílaba, por exemplo, ela 
DOTTA, C. S. S.; GARCIA, E. E. B.

respondia que estava faltando um pedaço da palavra, "faltava o começo", ao retirar outra sílaba da palavra, Maria conseguia identificar qual parte da palavra estava faltando. A partir dessa experiência, Freire percebeu que havia encontrado um caminho, passou a elaborar materiais e a desenvolver suas descobertas com grupos de pessoas que seriam alfabetizadas, priorizando sempre temas de interesse destas (/bid.). Sua primeira experiência de utilização de sua nova metodologia foi realizada com apenas cinco pessoas em uma escola de Recife, apesar de duas terem desistido, as três que deram continuidade mostraram resultados surpreendentes, nascendo, dessa forma, como explicita Haddad (2019), o que viria a ser chamado de "Método Paulo Freire de Alfabetização". Nas palavras de Freire:

Pensávamos numa alfabetização que fosse ao mesmo tempo um ato de criação, capaz de gerar outros atos cria-dores; uma alfabetização na qual o homem, que não é passivo nem objeto, desenvolvesse a atividade e a viva-cidade da invenção e da reinvenção, características dos estados de procura (FREIRE, 1979, p. 16).

Ainda segundo Haddad (2019), com os instrumentos já elaborados e testados em outros grupos pequenos, o método passa a ganhar visibilidade. Freire, em parceria com a equipe de Serviço de Extensão Cultural da Universidade de Recife, passa a escrever textos, que posteriormente foram consolidados em uma coletânea e publicados pela Revista de Cultura, n 4 de 1963 da Universidade de Recife, tendo sido um deles assinado por Freire, "Conscientização e Alfabetização: uma nova visão do processo", e utilizado como metodologia em algumas campanhas de alfabetização.

A campanha De pé no chão também se aprende a ler, na cidade de Natal, Rio Grande do Norte, promovida pelo então prefeito Djalma Maranhão, que definiu educação e cultura como meta número um de seu governo, foi uma grande marca da luta pela alfabetização, e uma das primeiras grandes campanhas a utilizar o método desenvolvido por Freire. Segundo Germano (1989, p. 96), o nome da campanha surge a partir de uma reportagem realizada pelo jornalista Expedito Silva, em que afirmava "que até de pé no chão também se aprende a ler, querendo dizer que de agora em diante educação não era mais privilégio, pois todos teriam acesso à escola, sem fardas, com qualquer roupa e até mesmo sem calçados". Ainda segundo Germano (1989, p. 96):

a Campanha significou, além das escolinhas e dos Acampamentos Escolares, a criação de bibliotecas populares, de praças de cultura, do Centro de Formação de Professores, do Teatrinho do Povo, da Galeria de Arte; significou a formação de círculos de leitura, a realização de encontros culturais, a reativação de grupos de danças folclóricas, a promoção de exposições de arte, a apresentação de peças teatrais, isto é, redundou numa organização cultural da cidade, onde o povo participava efetivamente e não apenas assistia como mero espectador.

Segundo Góes (1980, p. 56), no início da campanha havia uma grande resistência dos adultos analfabetos em irem para a escola, pois não aceitavam ficar sentados em bancos soletrando "Eva viu a uva", e essa era a escola que conheciam. Tal 
resistência levou os integrantes da campanha à compreensão do desafio de que se o adulto não vai à escola, a escola deveria ir até a casa do adulto. Quando então "os estudantes secundaristas entram em cena: equipe previamente treinada, professoresmeninos-voluntários, indo de casa em casa, de porta em porta, alfabetizavam pequenos grupos daqueles adultos. Funcionava então, a escola a domicílio" (/bid.). E assim foi feito, os adultos eram alfabetizados em casas, com o método Paulo Freire, até serem formados os círculos de cultura, compreendidos em 22 núcleos.

A partir da grande visibilidade que vinha ganhando, outras campanhas e movimentos se apoiaram no método criado por Freire, entre elas: a Campanha de Educação Popular da Paraíba (Ceplar) em 1961, o Movimento de Educação de Base (MEB), criado na Conferência Nacional dos Bispos do Brasil de 1961, os Centros Populares de Cultura (CPC) criados por cineastas e dramaturgos interessados em se aproximar dos setores populares, com a apresentação de filmes e peças teatrais que abordavam temas voltados à realidade brasileira. Dessa forma, a metodologia de Paulo Freire passava a ser difundida em âmbito nacional, vinculando sempre as ações de conscientização política aos trabalhos realizados que utilizassem seus métodos (HADDAD, 2019).

Em 1962, Freire recebeu a visita do Secretário de Educação do Rio Grande do Norte, Calazans Fernandes, que, a pedido do então Governador de Estado, conversou com Freire para que ele pudesse ajudar na alfabetização de adultos do Estado. São dados, nesse momento, os primeiros passos para a maior campanha de alfabetização conhecida no Brasil. A campanha conhecida como "As 40 horas de Angicos", cidade berço do Governador. Haddad (2019) afirma que Paulo Freire compreendia que a escolha da cidade tinha forte interesse em reforçar as bases eleitorais do governador, assim, uma das condições estipuladas por ele foi a de que não houvesse interferência política de nenhuma ordem. Os recursos para a campanha viriam de um programa lançado pelo então presidente americano John Kennedy - Aliança para o Progresso - o que acarretou muitas críticas a Paulo Freire, porém para ele se não houvesse interferência política não havia problema quanto ao programa financiar a campanha, e ele se assegurou de que seu relacionamento fosse exclusivamente com instâncias estaduais.

Em média trezentas pessoas se inscreveram no programa, que foi difundido principalmente pelas visitas dos estudantes às residências, mas também por conversas em locais públicos e por convites feitos através de alto-falantes. A solenidade de abertura, em 18 de janeiro de 1963, foi realizada pelo governador Aloízio Alves e pelo Secretário de Educação e Cultura Calazans Fernandes, com jornalistas e fotógrafos presentes.

O texto que segue é parte de uma reportagem publicada por Luiz Lobo na Tribuna da Imprensa do Rio, intitulada "A hora e a vez de Angicos".

Acontece em Angicos, cidadezinha do centro do Rio Grande do Norte, vinte e cinco estudantes acamparam por lá e estão fazendo a mais importante experiência em educação da história do Brasil. Estão tentando, em 40 horas, alfabetizar toda a cidade. 
DOTTA, C. S. S.; GARCIA, E. E. B.

Outro dia aparece por lá, um bando de moças e rapazes, universitários e ginasianos. E vão, de porta em porta, de conversa, querendo saber:

_O senhor sabe ler?

E vão avisando:

_ Nós vamos ensinar todo mundo a ler. E as aulas não vão demorar muitos dias. O senhor quer aprender?

_Então não quero môço?

_Prá que o senhor que aprender a ler?

Prá me livrar.

O texto demonstrava a importância política que a campanha teve em relação à conscientização dos analfabetos, que compreendiam o ato de aprender a ler e escrever como um ato de libertação.

Em pouco tempo a campanha repercutiu no Brasil inteiro. A alfabetização de 300 pessoas em 40 horas, uma experiência de alfabetização em massa, que significava não somente a alfabetização para a aprendizagem, como também a alfabetização para a formação da consciência; ou seja, não se tratava somente da formação de um grande número de pessoas, mas sim de uma mobilização popular que visava à conscientização da realidade vivida por cada sujeito alfabetizado, pois segundo afirmação do próprio Freire (2013, p. 33): "quando o homem compreende sua realidade, pode levantar hipóteses sobre o desafio dessa realidade e procurar soluções. Assim, pode transformála e com seu trabalho pode criar um mundo próprio: seu eu e suas circunstâncias".

No entanto, quanto mais Freire trabalhava e suas ideias se propagavam, muitos que preferiam um povo domesticado e acrítico resistiam aos seus ideais de conscientização.

\section{O GOLPE, NOS BRASILEIROS E NA VIDA DE PAULO FREIRE}

Haddad (2019) relata que a cerimônia de encerramento da Campanha foi um ato nacional, assim como a última hora aula, aberta pelo Presidente da República João Goulart, onde estavam presentes todos os governadores do Nordeste. No discurso do Governador do Estado, ele anuncia sua pretensão de espalhar a experiência por outras cidades e atingir a alfabetização de duzentos mil adultos. Porém, na mesma cerimônia, estava presente o general Humberto de Alencar Castelo Branco, que posteriormente foi empossado como Presidente da República com o golpe militar. Ao final da solenidade o general comenta com o secretário da Educação que:

O trabalho realizado em Angicos o preocupava, pois serviria para 'engordar cascavéis nesses sertões'. No jantar oferecido naquela noite de 1963, o general disse a Paulo que já havia sido alertado sobre o seu caráter subversivo - e que agora estava convencido por sua defesa de uma 'pedagogia sem hierarquia'² (p. 72).

Divulgada em todo país, e a partir da forte repercussão que teve a experiência em Angicos, em junho do mesmo ano Freire é convidado pelo Ministro da Educação e Cultura, Paulo de Tarso, a liderar uma ação nacional de alfabetização de adultos. Em setembro acontece o I Encontro Nacional de Alfabetização e Cultura Popular, com mais 
de 70 organizações participantes e representantes estaduais envolvidos com a alfabetização de adultos, dando sequência aos trabalhos mesmo com tantos desafios a serem ainda superados. Em janeiro de 1964, é instituído o novo decreto, o Programa Nacional de Alfabetização (PNA), pelo Ministério da Educação e Cultura, que deveria ser desenvolvido pelo Sistema Paulo Freire. Com a meta de alfabetizar cinco milhões de pessoas no Brasil, garantindo assim o direito de votar aos até então analfabetos, o cenário das próximas eleições seria composto também pela massa dos setores populares críticos e conscientes. Nesse sentido, tanto o PNA como Paulo Freire passam a ser vistos como uma ameaça de perda dos privilégios dos setores conservadores apoiados pelos militares, corrobora Haddad (2019).

O momento político, ainda seguindo os pensamentos de Haddad (2019), vinha se articulando de forma criativa e propícia para o desenvolvimento de uma educação crítica e para a cultura popular, que agora já vinha se espalhando inclusive pela América Latina. Entretanto, com o golpe militar ocorrido em abril de 1964 o PNA foi imediatamente desarticulado e Paulo Freire preso. Se iniciava no Brasil um retrocesso de todo o processo até então alcançado, e, muito além disso, uma enorme repressão a todos que manifestassem ideias contrárias aos chefes do governo.

Humberto de Alencar Castelo Branco assumiu a presidência com o golpe e Paulo Freire passa então a ser acusado, juntamente com outros membros do PNA, de propagar ideias contrárias ao regime democrático, e estar envolvido com o comunismo. Em 16 de junho de 1964, Freire foi preso, sem nenhuma acusação concreta - ao total dos dias em que esteve detido, somaram-se 70 dias de reclusão. Sua vontade era permanecer no Brasil, mas após um novo mandado de prisão argumentando que estivesse envolvido em subversão, que seu método não teria validade e nem originalidade, e que seria um aliciador do marxismo, Freire decide deixar o país. Convidado a trabalhar na Bolívia como assessor de educação voltada ao ensino de adultos, Freire aceita o convite e assim inicia seu exílio, que duraria 15 anos. "Um dia, proibido de ser, me vi longe de minha terra: Exílio" (FREIRE, 2015, p. 45).

Infelizmente o golpe paralisou - congelou - as iniciativas de educação de adultos. Alguns programas foram implementados durante o período em que se manteve a ditadura militar, porém com objetivos totalmente contrários ao processo de democratização anteriormente iniciado. Após várias experiências de alfabetização fracassadas, o governo percebia, segundo Haddad e Di Pierro (2000), que precisava responder às questões do direito que vinha se destacando como legítimo, mas também com estratégias para atender os interesses do modelo de hegemonia socioeconômica que o regime militar vinha acentuando. Para tanto, foi implantado, em 15 de dezembro de 1967, o Movimento Brasileiro de Alfabetização (MOBRAL). Ainda segundo os autores, inicialmente o movimento apresentava uma proposta pedagógica, mas as pressões do regime militar para atender os objetivos e interesses políticos levaram o programa a apresentar um caráter técnico de formação em massa. Até 1970, a função do Mobral era o financiamento e orientação técnica para programas de alfabetização, porém sem ter sido colocado em prática. Segundo Paiva (1981), é somente no ano de 1970 que o Mobral passa a ser um organismo executor de um programa de alfabetização, tornando- 
DOTTA, C. S. S.; GARCIA, E. E. B.

se, junto com a expansão do Ensino Superior, os pilares do governo militar, mas com objetivos distintos.

\begin{abstract}
Enquanto a expansão do ensino superior visava, entre outros objetivos, atender às demandas das classes médias por esse nível de ensino e neutralizar o movimento estudantil, o Mobral foi montado como uma peça importante na estratégia de fortalecimento do regime, que buscou ampliar suas bases sociais de legitimidade junto as classes populares, num momento em que ela se mostrava abalada junto às classes médias (PAIVA, 1981, p. 85).
\end{abstract}

Nesse aspecto, segundo a autora, o Mobral fez com que os empresários acreditassem que o programa não somente "livraria o país da chaga do analfabetismo, mas que simultaneamente, realizaria uma ação ideológica capaz de assegurar a estabilidade do status quo e permitiria às empresas contar com amplos contingentes de força de trabalho alfabetizada" (/bid., p. 100).

Percebe-se a grande diferença de objetivos das campanhas realizadas anteriormente ao golpe para o movimento que o governo militar realizou em prol da educação de adultos, que reprimia o método Paulo Freire, interrompendo uma história que vinha ganhando espaço e força para a formação de sujeitos conscientes que buscavam estabelecer um lugar de direito diante das conquistas que haviam se iniciado. Gadotti (2004) explica que, segundo Freire, para se chegar a essa consciência, que é ao mesmo tempo desafiadora e transformadora, são imprescindíveis o diálogo crítico, a fala e a convivência.

Foram 15 anos de exílio, tempo em que aquilo que deveria ter acontecido aqui no Brasil aconteceu pelo mundo: o reconhecimento de seu trabalho. Haddad (2019) explica que Freire se destacou em inúmeros países; passou parte desse tempo vivendo na Bolívia, Chile, Estados Unidos e Genebra, foi convidado por muitas Universidades a realizar trabalhos, palestras e participar de congressos e seminários. Não cabe aqui situar todas as suas experiências durante esses 15 anos, mas é importante destacar que durante o tempo que viveu em Genebra, Freire atuou no departamento de educação do Conselho Mundial de Igrejas (CMI), o que o levou a realizar os trabalhos que talvez tenham sido os de maior significado para ele. Realizados em alguns países da África continente que estava sendo marcado pelas lutas de libertação, com destaque a GuinéBissau, onde pôde colocar em prática, não que não o tenha feito nos outros países por onde passou, seu método de alfabetização de adultos, com seu viés libertador e conscientizador.

Foi também durante o exílio que Paulo Freire escreveu várias de suas obras, entre elas a que mais se destacaria mundialmente: "Pedagogia do Oprimido", livro que foi traduzido para mais de 20 idiomas. Para Giroux (1998, p. 191), o nome de Paulo Freire "tornou-se sinônimo do próprio conceito e prática de pedagogia crítica [...] tem-se tornado a referência padrão para engajar no que é muitas vezes referido como o ensino para o pensamento crítico, pedagogia dialógica ou alfabetização crítica".

A VOLTA AO BRASIL DEPOIS DE PERCORRER O MUNDO ENSINANDO

Inter-Ação, Goiânia, v.46, n. ed.especial, p. 1052-1067, set. 2021. Disponível em: <http://dx.doi.org/10.5216/ia.v46ied.especial.67986>. 
No ano de 1979, Paulo Freire volta ao Brasil, conforme registra Almino Affonso em um artigo escrito para a Folha de São Paulo, de 7 de agosto de 1979, intitulado: "Um educador engajado". Esse artigo foi publicado por Haddad (2019), do qual destacamos:

\begin{abstract}
Chega hoje a São Paulo, depois de mais de quinze anos de exílio, o professor Paulo Freire, há muitos há de causar estranheza, que um educador, desvinculado de uma militância política em seu sentido estrito, tenha estado impossibilitado de regressar à terra natal durante tanto tempo. [...] com uma bagagem carregada de serviços prestado aos povos da América Latina, e da África, com uma obra consagrada, em sucessivas edições, em vinte idiomas, com título de doutor honoris causa pela Universidade de Louvain (Bélgica), Universidade Livre de Londres (Inglaterra), Universidade de Michegan (Estados Unidos e Universidade de Genebra (Suíça), com uma grandeza que decorre, sobretudo, de haver posto sempre o seu pensamento a serviço da libertação do homem (HADDAD, 2019, p. 137).
\end{abstract}

Já no Brasil, seu trabalho manteve-se voltado à educação popular e à educação de adultos, lecionando em programas de pós-graduação em várias universidades. Com as eleições de 1988, ao ser eleita para a prefeitura de São Paulo pelo Partido do Trabalhadores (PT), Luiza Erundina convida Paulo Freire para assumir a Secretaria de Educação, indicação que, segundo a Prefeita, "significava a reparação de duas injustiças: o exílio do educador e o esquecimento de seu método de alfabetização" (HADDAD, 2019, p. 191). Durante o tempo em que esteve como Secretário, entre as suas principais iniciativas estão a criação do Programa de Alfabetização de Adultos (PAD) e o Movimento de Alfabetização de Jovens e Adultos (MOVA). Freire esteve à frente da Secretaria até 27 de maio de 1991, confessando seu desejo de ficar mais tempo em casa, poder se dedicar mais a seus livros e já cansado após os desgastes que o cargo o atribuía. Com tempo novamente, volta à escrita de novos livros, sendo em abril de 1997 lançada a que seria sua última obra: "Pedagogia da Autonomia: saberes necessários à prática educativa". Em 1992 é fundado, por brasileiros e estrangeiros, o Instituto Paulo Freire, tendo hoje sedes espalhadas por 15 países.

No dia 2 maio, do mesmo ano, 1997, Freire morre em consequência de problemas cardíacos, deixando um legado de luta e exemplo, ficando conhecido na história do país como o brasileiro mais reconhecido no exterior, com 34 títulos de doutor honoris causa por universidades do Brasil e do exterior. Em 2009 foi reconhecido como anistiado político pela Comissão da Anistia do Ministério da Justiça. Mesmo depois de sua morte, alguns livros ainda foram escritos a partir de textos, artigos e cartas deixados por ele. Jaime José Zitkoski, Danilo Streck, e Euclides Redin organizaram a obra "Dicionário Paulo Freire", com mais de duzentos verbetes escritos por inúmeros autores convidados, constituindo-se uma importante fonte de referências das ideias e conceitos do autor. E em abril de 2012, Paulo Freire foi intitulado Patrono da Educação do Brasil. Haddad (2019, p. 219) apresenta um estudo realizado em 2016 pelo professor Elliott Green da London School of Economics que mostrou que o livro Pedagogia do Oprimido era, na ocasião, a terceira obra mais citada em trabalhos da área de ciências humanas no 
DOTTA, C. S. S.; GARCIA, E. E. B.

mundo, atrás apenas do filósofo Thomas Kuhn e do sociólogo Everett Rogers, ambos estadunidenses.

\section{AS CONTRIBUIÇÕES DE FREIRE NA ANDARILHAGEM DA PESQUISA}

A pesquisa que embasa o artigo aqui apresentado trata do direito à continuidade dos estudos para egressos da Educação de Jovens e Adultos em contexto de disparidades nos processos seletivos de ingresso no Ensino Superior. Para denunciar isso, busca em Paulo Freire a sustentação de que a educação é uma ferramenta que deve ajudar os sujeitos a emergir do processo de acomodação para inserirem-se de forma crítica em seu processo histórico, uma educação que "não descuidasse da vocação ontológica do homem, a de ser sujeito e não objeto" (FREIRE, 2013, p. 72). Freire também está presente na pesquisa quando analisa a inserção de estudantes oriundos da EJA no Ensino Superior, desde o sentido ontológico do direito de ser mais, de buscar por aquilo que sonha, de transformar seu desejo em concretude.

A partir da análise da Constituição Federal Brasileira, a qual trata, em seu artigo 208 , inciso V, do acesso ao ensino superior, afirma o direito de "acesso aos níveis mais elevados do ensino, da pesquisa e da criação artística, segundo a capacidade de cada um" (BRASIL, 1988, p. 72), assim como a Declaração Universal de Direitos Humanos, que afirma que essa igualdade de acesso "deve ser baseada no mérito, capacidade, esforços, perseverança e determinação mostradas por aqueles que buscam o acesso à educação" (ONU, 1960 apud UNESCO, 1998, p. 3). Nesse sentido, e apoiadas nos conceitos de Paulo Freire, compreendemos, que ao mesmo tempo que esses documentos afirmam o direito ao acesso, também limitam e impulsionam a desigualdade de oportunidades, pois não esclarecem quais seriam os determinantes de mérito, esforço, perseverança e capacidade aos quais os documentos se referem, e nem quais os mecanismos que atuam para determinar essas condições. O discurso acerca dos méritos do acesso à Educação Superior, segundo Apple (2008), fundamenta-se em uma ideologia educacional liberal, que pode até demonstrar um melhoramento social, mas com uma ideologia meritocrata contrária: "A política educacional liberal - com sua ética de sucesso individual baseada supostamente no mérito - é vista como uma linguagem de justificação, como uma forma ideológica, em vez de ser uma descrição bastante precisa de como a educação funciona" (APPLE, 2008, p. 51).

Visto dessa forma, entende-se que, para alcançar o Ensino Superior, cabe ao próprio estudante dispor dos recursos necessários, assim como, se acaso não o alcance, que fique certificado de que é puramente sua a responsabilidade, a culpabilidade. É nesse sentido que analisamos as ações e programas de acesso ao Ensino Superior como contraditórios e desiguais, pois as políticas públicas podem até afirmar esse direito, porém a desigualdade, tanto social como educacional do Brasil, demostra que o número de ingressos nesse nível educacional ainda é extremamente limitado, diante do número de estudantes que concluem o Ensino Médio no país, principalmente quando se refere a estudantes que concluíram seus estudos na modalidade EJA. Entretanto, ao determinar que esse acesso deve ser baseado no mérito, capacidade, esforços, perseverança e determinação mostradas por aqueles que buscam o acesso à educação, o sistema acaba por culpabilizar os próprios estudantes por não alcançarem o ingresso ao Ensino Superior.

Inter-Ação, Goiânia, v.46, n. ed.especial, p. 1052-1067, set. 2021. Disponivel em: <http://dx.doi.org/10.5216/ia.v46ied.especial.67986>. 
Paulo Freire contribui nesse pensamento quando se refere à falsa generosidade do opressor, que impõe o sentimento de culpa naquele que sofre a opressão e complementa afirmando que "com esta generosidade falsa, além de estar pretendendo a manutenção de uma ordem injusta e necrófila, estará querendo "comprar" a sua paz" (FREIRE, 2005, p. 166). Em outro exemplo, Freire nos fala sobre "a assunção da culpa pelo seu fracasso", quando as pessoas atribuem a si mesmas essa responsabilidade, e não percebem a "perversidade do sistema social, econômico, político em que vivem, mas na sua própria incompetência. Enquanto sentirem assim, pensarem assim e agirem assim, reforçam o poder do sistema. Se tornam coniventes da ordem desumanizante" (FREIRE, 1996, p. 86).

Portanto, é a manipulação como instrumento de conquista que faz com que se perceba exatamente como o discurso pretende eximir o sistema de ingresso de qualquer responsabilidade quanto à condição, ou não, da obtenção de acesso, permanência e conclusão dos níveis mais elevados de educação.

\section{CONSIDERAÇÕES FINAIS}

Fragmentos da vida de Freire aqui apresentados demonstram que a sua contribuição para a educação de adultos foi muito além das fronteiras do Brasil; Freire deixou sua marca e seu legado no mundo. Criador de inúmeras concepções, entre elas a que talvez mais se destaque, a concepção bancária de educação, em que "a educação se torna um ato de depositar, em que os educandos são os depositários e o educador o depositante" (FREIRE, 2005, p. 66), sendo oposta à concepção problematizadora e humanizadora. Para Gadotti (2004), Freire era um educador otimista e crítico e sua obra deve servir de estímulo para prosseguirmos na tarefa de reconstrução social, na qual o educador tem um papel decisivo. Arroyo (2020) também destaca a importância da contribuição de Paulo Freire para uma educação humanizadora de sujeitos coletivos. "Paulo Freire construiu sua reflexão e prática educativa, referida sempre aos novos sujeitos sociais, políticos, aos movimentos de jovens, de trabalhadores e camponeses dos anos de 1960/1970, aos movimentos culturais de libertação do povo da África e da América Latina (ARROYO, 2020, p. 27)".

Para Garcia (2011, p. 279), Freire nos mostrou que "ensinar é criar possibilidades para a produção de conhecimento, em que a participação ativa de todos os sujeitos do espaço-tempo escolar subjaz à proposta pedagógica de uma educação autônoma e emancipatória".

Paulo Freire se constitui como a principal marca de visibilidade para a educação de adultos, colocando o sujeito juntamente com sua vivência no seu lugar de protagonismo social, fazendo entender que somente a educação tem a condição de tirar as pessoas do mero anonimato político para uma posição de sujeito crítico e antagônico, ao passo que possibilita compreender o processo de desumanização em que está submetido e realizar uma reflexão dos processos de libertação e emancipação. $O$ que possibilita, ainda, se perceberem não mais responsáveis por sua condição de subalternização, mas responsáveis pelas mudanças que a conscientização os fará perceber. 
DOTTA, C. S. S.; GARCIA, E. E. B.

Por fim, sinalizamos que Freire como homem do mundo, como ser humano e como educador buscou a defesa da educação e a possibilidade de com ela mudar vidas. Freire se constituiu como um dos maiores educadores dos últimos tempos, ele ensinou muito mais do que a importância de saber ler as letras, ensinou a ler o mundo para poder transformá-lo por meio da ação libertadora.

Artigo recebido em: 01/03/2021

Aprovado para publicação em: 29/06/2021

THE HISTORICAL CONTRIBUTIONS OF PAULO FREIRE WITH REGARDS TO THE ADULT'S RIGHT TO EDUCATION AND HIS METHOD OF LITERACY

ABSTRACT: This text deals with the life trajectory of the educator Paulo Freire, explains his story, not only as a social man, as he is known, but as a human being and educator, based on a bibliographical review made around the story of his life, based on the studies by Sergio Haddad (2019); Moacir Gadotti (2004) and in Freire's own works. This study is part of a Professional Master's Degree in Education research, which investigates the students of a University education course that passed in their school trajectories through Educação de Jovens e Adultos - EJA (Youth and Adult Education). For this study to be carried out, the theoretical foundation of Paulo Freire's concepts was fundamental, which aroused our interest not only in understanding the concepts themselves, but also in knowing their story, getting closer to the life of this popular educator who was dedicated to excluded, oppressed and illiterate.

KEYWORDS: Paulo Freire. History. Literacy. Youth and Adult Education.

LAS CONTRIBUCIONES HISTÓRICAS DE PAULO FREIRE AL DERECHO DEL ADULTO A LA EDUCACIÓN Y SU MÉTODO DE ALFABETIZACIÓN

RESUMEN: Este texto propone presentar una síntesis sobre la trayectoria de vida del educador Paulo Freire, presentando su historia, no sólo como hombre social, como se lo conoce, sino como ser humano y educador, basado en una revisión bibliográfica realizada en torno de su história de vida, fundamentada en los estudios de Sérgio Haddad (2019), Moacir Gadotti (2004) y en las obras del próprio Paulo Freire. Este estudio forma parte de una investigación del Máster Profesional en Educación, que investiga acerca de los estudiantes de un curso de educación superior que han pasado en sus trayectorias escolares a través de la Educación de Jóvenes y Adultos - EJA. Para que este estúdio sea realizado, fué necesária la fundamentación teórica con los conceptos de Paulo Freire, lo que nos despertó el interés no solamente en compreender los conceptos en sí, sino en conocer su história, nos aproximar mas a la vida de ese educador popular que se dedicó a los excluídos, oprimidos y analfabetos.

PALABRAS CLAVE: Paulo Freire. Historia. Alfabetización. Educación de Jóvenes y Adultos. 
NOTAS

1 - Não foi encontrada a data de publicação da reportagem.

2 - A visão e o posicionamento do general quanto ao pensamento e as iniciativas de Freire se confirmaram após o golpe militar, com a rapidez com que ele foi preso no ano seguinte quando o general Humberto de Alencar Castelo Branco assume o governo durante o golpe militar.

\section{REFERÊNCIAS}

APPLE, M. W. Ideologia e Cultura. 3 ed. Porto Alegre: Artimed, 2008.

ARROYO, M. G. Outros Sujeitos, Outras Pedagogias. 2 ed. $5^{\text {a }}$ reimpressão. Petrópolis: Vozes, 2020.

BRASIL. Constituição (1988). Constituição da República Federativa do Brasil. Brasília, DF: Senado Federal: Centro Gráfico, 1988.

CASALI, A.; BARRETO, V. Prefácio. In:FREIRE, Ana Maria Araújo. Paulo Freire: Uma história de Vida. Indaiatuba, SP. Primeira edição, 2006.

FREIRE, P. À sombra desta mangueira. 11 Ed. Rio de Janeiro: Paz e Terra, 2013.

FREIRE, P. Conscientização: teoria e prática da libertação: uma introdução ao pensamento de Paulo Freire. Trad. de Kátia de Mello e Silva. São Paulo: Cortez \& Moraes, 1979.

FREIRE, P. Educação de adultos: algumas reflexões. In: GADOTTI, Moacir e POMÃO, José E. educação de Jovens e Adultos: teoria, prática e proposta. 12 ed. São Paulo: Cortez, 2011.

FREIRE, P. Educação e Mudança. Rio De Janeiro: Paz e Terra, 2013.

FREIRE, P. Pedagogia da Autonomia: saberes necessários à prática educativa. 39 ed. São Paulo: Paz e Terra, 1996.

FREIRE, P. Pedagogia da Esperança: Um reencontro com a Pedagogia do oprimido. 27 ed. Rio de Janeiro: Paz e Terra, 2020.

FREIRE, P. Pedagogia do Oprimido. 41 ed. Rio de Janeiro: Paz e Terra, 2005. 
DOTTA, C. S. S.; GARCIA, E. E. B.

GADOTTI, M. Educação de Jovens e Adultos: correntes e tendências. In: GADOTTI, M.; POMÃO, J. E. Educação de Jovens e Adultos: teoria, prática e proposta. 12 ed. São Paulo: Cortez, 2011.

GADOTTI, M. Convite à leitura de Paulo Freire. 2 ed. São Paulo: Editora Scipione, 2004.

GARCIA, E. E. B. A política de Educação de Jovens e Adultos em São Leopoldo/RS, na Perspectiva de seus Sujeitos. 2011. 302 f. Tese de Doutorado do Programa de PósGraduação da Universidade do Vale do Rio dos Sinos - UNISINOS. São Leopoldo/RS. 2011.

GERMANO, J. W. Lendo e Aprendendo: a Campanha de Pé no Chão. 2 ed. São Paulo: Cortez, 1989.

GIROUX, H. Paulo Freire e a política de pós-colonialismo. In: MCLAREN, P; LEONARD, P; GADOTTI, M. (Orgs). Paulo Freire: poder, desejo e memórias da libertação. Porto Alegre: ArtMed, 1998.

GÓES, M. de. Campanha De Pé no Chão Também se Aprende a Ler (1961 - 1964): Uma escola democrática. Rio de Janeiro: Civilização Brasileira, 1980.

HADDAD, S; DI PIERRO, M. C. Escolarização de Jovens e Adultos. Rev. Bras. Educ. [online]. 2000, n.14, pp.108-130. ISSN 1413-2478. Disponível em: $<$ https://www.scielo.br/scielo.php?pid=S1413-

$24782000000200007 \&$ script=sci_abstract\&tlng $=$ pt $>$. Acesso em: 23 fev. 2021

HADDAD, S. O Educador: Um perfil de Paulo Freire. São Paulo: Todavia: 2019.

PAIVA, V. História da Educação Popular no Brasil: educação popular e educação de adultos. 7 ed. São Paulo: Loyola, 2015.

PAIVA, V. MOBRAL: Um desacerto autoritário. In: Síntese: Revista de Filosofia. v. 8 In. 23 $1981 . \quad$ Disponível em: $<$ http://www.faje.edu.br/periodicos/index.php/Sintese/issue/view/178>. Acesso em: 19 fev. 2021.

STRECK, D. R.; REDIN, E.; ZITCONKI, D. J. (Orgs). Dicionário Paulo Freire. Belo Horizonte: Autêntica, 2008.

UNESCO. Declaração Mundial sobre Educação Superior no Século XXI: Visão e Ação. Paris: UNESCO, 1998. 
Carla luz Salaibb Dotta: Professora da Prefeitura Municipal de Capão da Canoa e professora da Prefeitura Municipal de Imbé. Possui graduação em Educação do Campo pela Universidade Federal do Rio Grande do Sul (UFRGS) e graduação em Pedagogia pela Faculdade do Grupo UNIASSELVI. Especialização em Educação de Jovens e Adultos (EJA) e Mestranda no Programa de Pós-Graduação - Mestrado Profissional em Educação da Universidade Estadual do Rio Grande do Sul (UERGS).

Orcid: https://orcid.org/0000-0002-6057-8846

E-mail: carlasalaibb@gmail.com

Elisete Enir Bernardi Garcia: Possui graduação em Pedagogia (1996). Especialização em Educação Profissional Técnica de Nível Médio na Modalidade de Educação de Jovens e Adultos - PROEJA - Universidade Federal do Rio Grande do Sul - UFRGS (2006-2007) e Mestrado em Educação pela Universidade do Vale do Rio dos Sinos UNISINOS (2005). Doutorado em educação (2007-2011) pela UNISINOS.

Orcid: https://orcid.org/0000-0002-1211-3059

E-mail: elisete.bernardi@smail.com

Este periódico utiliza a licença Creative Commons Attribution 3.0, para periódicos de acesso aberto (Open Archives Initiative - OAI). 